\title{
Rubella-associated arthritis. I. Comparative study of joint manifestations associated with natural rubella infection and RA 27/3 rubella immunisation
}

\author{
AUBREY J TINGLE, ${ }^{1}$ MARILYN ALLEN, ${ }^{1}$ ROSS E PETTY, \\ G DONALD KETTYLS, AND JANET K CHANTLER ${ }^{3}$
}

From the ${ }^{1}$ Divisions of Immunology and ${ }^{2}$ Rheumatology of the Department of Paediatrics, and the $\overrightarrow{\vec{\omega}}$ ${ }^{3}$ Department of Pathology, University of British Columbia; and the ${ }^{4}$ Provincial Laboratory of Public Health, Vancouver, British Columbia, Canada

SUMMARY Joint manifestations observed during the course of a prospective RA $27 / 3$ rubella immunisation trial were compared with those observed during an intercurrent wild rubellao epidemic in an outlying community. Among 44 rubella haemagglutination inhibition (HAI) negative females ranging in age from 17 to 33 years who received rubella vaccine, six $(13 \cdot 6 \%)_{\mathbb{D}}^{\text {T }}$ developed acute polyarticular arthritis within two to four weeks postvaccine and two $(4.5 \%)$ hado continuing or recurrent arthropathy lasting longer than 18 months. In contrast, among 23 femaleso ranging in age from 11 to 39 years undergoing wild rubella infection, $12(52 \cdot 2 \%)$ developed acute polyarticular arthritis and seven $(30.4 \%)$ had recurrent arthropathy 18 months postinfectio .0 Among 23 males ranging in age from 13 to 54 years undergoing wild rubella infection, only two $(8.7 \%)$ developed acute arthritis and both individuals had continuing joint manifestations $\$ 80$ months postinfection. Wild rubella infection in adult populations is associated with a higher incidence, increased severity, and more prolonged duration of joint manifestations than is seeno after RA $27 / 3$ rubella immunisation.

Key words: rubella, rubella vaccine, rubella virus, infectious arthritis.

Rubella virus infection has long been associated with musculoskeletal pain syndromes ranging in severity from mild muscle and joint aching of a few days duration to the development of frank arthritis with long-term residual joint disease. ${ }^{1-7}$ Symptoms usually begin within one week of the appearance of rash in wild rubella infection or in the two- to four-week period after rubella immunisation.

The incidence is rare in infants and young children but increases in frequency in postpubertal age groups, ${ }^{1}{ }^{2}$ when it is the principal adverse reaction associated with adult rubella immunisation.

The occurrence of a wild rubella epidemic during the course of a prospective rubella immunisation study provided an unusual opportunity for a direct comparison of the rheumatological manifestations

Accepted for publication 24 July 1985

Correspondence to Dr Aubrey Tingle, Division of Immunology, Room 2K5, Children's Hospital, 4480 Oak Street, Vancouver V6H 3V4, BC, Canada. observed after infection with wild and vaccine strains of the rubella virus. This comparison formse the basis for the present report.

\section{Patients and methods}

PATIEN TS

The rubella vaccine study group consisted of $44{ }^{\circ}$ females ranging in age from 17 to 33 years (mean age $23 \cdot 1$ ) who were attending the student health service at the University of British Columbia. NoN members of this group had previously received rubella immunisation and all had negative preimmunisation rubella haemagglutination inhibition (HAI) $\omega$ titres $(<1 / 8)$. After a decision by the student to undergo rubella immunisation a clinical history was? obtained and the RA 27/3 rubella vaccine (Meruvax II, Merck Sharp and Dohme) was administered by.health service staff. Clinical follow up was carried out by direct patient interview and examination by one member of the investigative team at one, two $\frac{?}{10}$ 
three, four, five, six, 12 , and 24 weeks and 18 months postimmunisation.

The wild rubella infection group consisted of 46 individuals, who developed a typical rubella rash, sore throat, and posterior cervical lymphadenopathy during a four- to six-week period in the autumn of 1982. This group included 37 high school students, five family members, and four members of school staff. All individuals were routinely interviewed by local public health personnel. Confirmation of rubella virus infection was carried out by rubella HAI seroconversion or virus isolation from throat swabs in each of 26 subjects (11 females, 15 males) randomly selected for laboratory study during the epidemic period. The wild rubella group consisted of 23 females and 23 males ranging in age from 11 to 54 years (mean age 19.2). All individuals were interviewed and examined during the acute illness by public health staff and at six months and 18 months postinfection by members of the investigative team. A designation of arthritis required the observation or clinical history of joint swelling or loss of range of motion with heat or erythema, while arthralgia referred to the presence of localised joint pain alone. A prior history of rubella immunisation was found in two members of this group, with documented HPV-77 DE/5 rubella vaccine administration seven and 11 years respectively before the wild rubella infection.

\section{RUBELLA SEROLOGY AND ISOLATION} STUDIES

Rubella HAI and sucrose density gradient (SDG) studies on acute and convalescent sera were carried out by techniques previously described. ${ }^{7}$ Detection of rubella antibody of the IgM class was assessed by SDG centrifugation of serum with HAI analysis of IgM-containing fractions. Rubella virus isolation studies on throat swabs taken during the acute illness were carried out with African green monkey kidney (AGMK) culture and by ECHO 11 interference techniques. ${ }^{8}$

STATISTICAL METHODS

Statistical assessment of incidence rates of joint signs or symptoms after rubella infection was performed by $\chi^{2}$ analysis.

\section{Results}

INCIDENCE OF JOINT SYMPTOMS

In the rubella vaccine study group objective evidence of arthritis (joint effusion, limitation of movement, heat, or erythema) was recorded in six of $44(13.6 \%)$ individuals, while joint pain alone was noted in 18 of $44(40.9 \%)$ (Table 1$)$. The onset of joint symptoms occurred between nine and 27 days (mean 15.3 days) postimmunisation. There were no significant differences in mean age at the time of immunisation among the groups developing arthritis (mean age 23.3 years), arthralgia (mean age 23.7 years), or no joint symptoms (mean age 23.0 years). The number of joints affected at the time of onset was higher in individuals with acute arthritis $($ mean $=6 \cdot 2)$ than in those developing arthralgia alone $($ mean $=3 \cdot 2)$. Among the members of the wild rubella infection group laboratory confirmation was sought by seroconversion or rubella virus isolation techniques in 26 cases and was successful in each instance. No differences were noted in the frequency and severity of joint manifestations between those in whom rubella infection was serologically or virologically confirmed and those in whom confirmation was not sought. Within the wild rubella infection group as a whole, arthritis was observed in 14 of 46 individuals $(30.4 \%)$, while arthralgia alone was observed in a further 14 individuals. Females experienced more severe joint complaints than males, with 12 of 23 females $(52 \cdot 2 \%)$ having objective evidence of arthritis, while only two of 23 males $(8 \cdot 7 \%)$ did so.

Table 1 Acute joint manifestations after rubella immunisation or wild rubella infection

\begin{tabular}{|c|c|c|c|c|}
\hline \multirow{2}{*}{$\begin{array}{l}\text { Rubella infection } \\
\text { group }\end{array}$} & \multirow[t]{2}{*}{$n$} & \multicolumn{3}{|c|}{ Acute rubella-associated joint manifestations } \\
\hline & & None & Arthralgia* & Arthritis ${ }^{\dagger}$ \\
\hline \multicolumn{5}{|l|}{ Rubella vaccine } \\
\hline Females & 44 & $20(45 \cdot 5 \%)$ & $18(40 \cdot 9 \%)$ & $6(13 \cdot 6 \%) \ddagger$ \\
\hline \multicolumn{5}{|l|}{ Wild rubella } \\
\hline Females & 23 & $8(34 \cdot 8 \%)$ & $3(13 \cdot 0 \%)$ & $12(52 \cdot 2 \%) \ddagger$ \\
\hline Males & 23 & $10(43 \cdot 5 \%)$ & $11(47 \cdot 8 \%)$ & $2(8 \cdot 7 \%)$ \\
\hline Overall & 46 & $18(39 \cdot 1 \%)$ & $14(30.4 \%)$ & $14(30 \cdot 4 \%)$ \\
\hline
\end{tabular}

*Pain only with no objective signs.

†Joint swelling, effusion, or loss of range of movement with heat or erythema. $\neq \mathrm{p}<0 \cdot 001$. 
DISTRIBUTION OF JOINT IN VOLVEMENT

The distribution of affected joints was very similar in both the rubella vaccine and wild rubella study groups (Table 2). Arthritis involving the knees and finger joints occurred most commonly. In contrast, arthralgias involved interphalangeal joints most frequently, with knees, wrists, elbows, and other joints affected at a lower frequency.

DURATION OF JOINT SYMPTOMS

Among 44 members of the rubella vaccine group, seven $(15.9 \%)$ had two or more recurrent episodes of arthritis or arthralgia postimmunisation (Fig. 1). By six months postimmunisation four individuals were
Table 2 Distribution of joint involvement during acute postrubella arthritis

\begin{tabular}{|c|c|c|}
\hline $\begin{array}{l}\text { Joints } \\
\text { affected }\end{array}$ & $\begin{array}{l}\text { Rubella* vaccine } \\
\text { group }\end{array}$ & $\begin{array}{l}\text { Wild rubella } \\
\text { group }\end{array}$ \\
\hline Fingers & $15(63 \%)$ & $18(64 \%)$ \\
\hline Knees & $14(58 \%)$ & $17(61 \%)$ \\
\hline Elbows & $3(13 \%)$ & $8(29 \%)$ \\
\hline Wrists & $9(38 \%)$ & $7(25 \%)$ \\
\hline Ankles & $6(25 \%)$ & $5(18 \%)$ \\
\hline Hips & $6(25 \%)$ & $4(14 \%)$ \\
\hline Toes & $4(17 \%)$ & $3(11 \%)$ \\
\hline Shoulders & $6(25 \%)$ & $2(7 \%)$ \\
\hline Others & $6(25 \%)$ & $3(11 \%)$ \\
\hline
\end{tabular}

*RA $27 / 3$ vaccine.
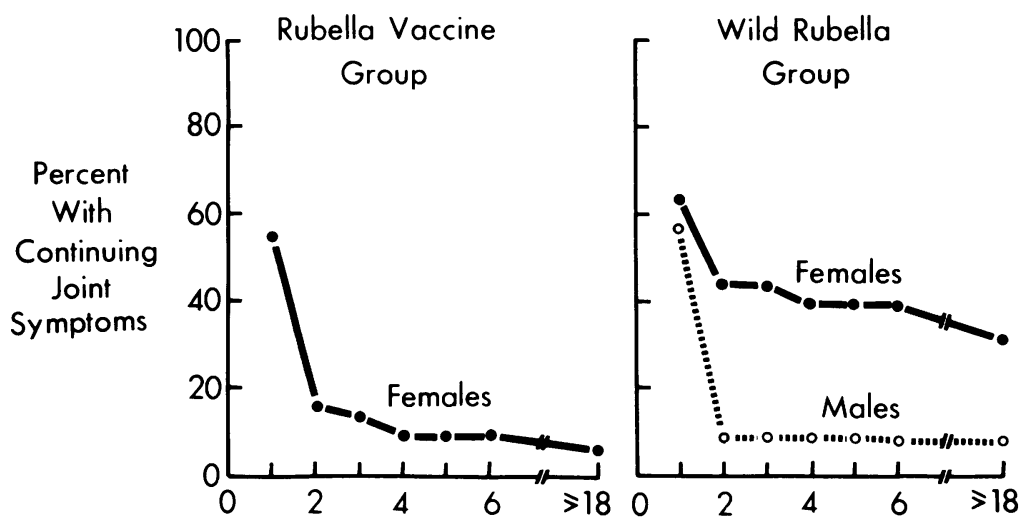

Time Following Rubella Infection (months)

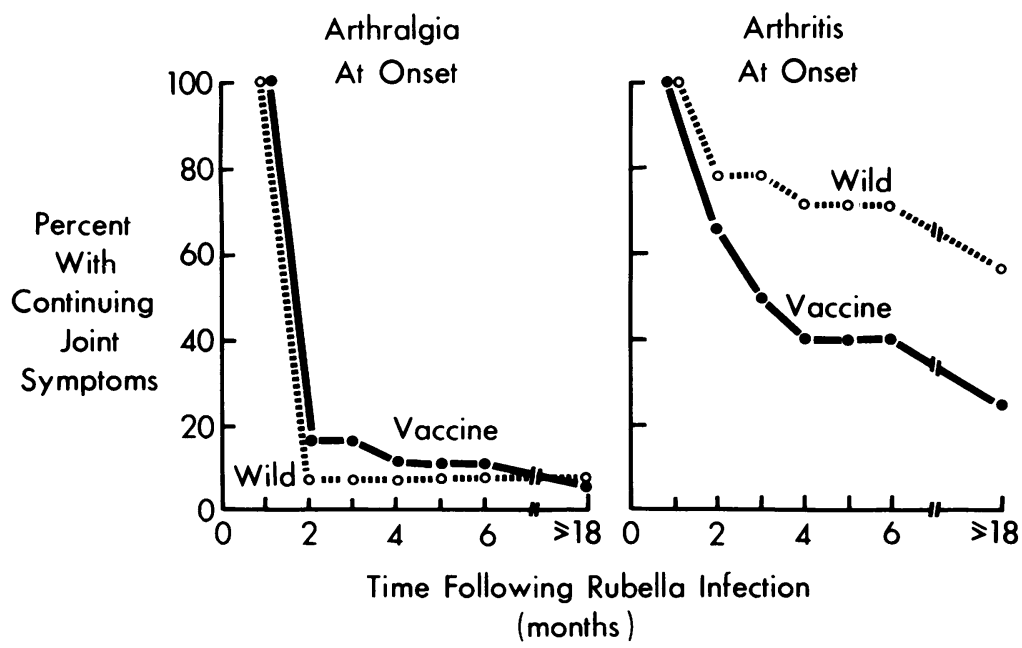

Fig. 1 Duration of joint symptoms after rubella immunisation and 0 wild rubella infection.

Fig. 2 Duration of joint sympton in relation to the nature of presenting joint manifestations. 
having recurrent episodes of joint symptoms (one with arthritis and three with arthralgias). By 18 to 24 months postimmunisation two individuals $(4.5 \%)$ were continuing to experience recurrent episodes of arthritis or arthralgia. Recurrent joint symptoms were noted at a higher frequency in those presenting initially with more severe disease, i.e., objective arthritis, than in those presenting simply with arthralgia (Fig. 2).

Among members of the wild rubella group 10 of 23 $(43.5 \%)$ females and two of $23(8.7 \%)$ males experienced two or more episodes of joint symptoms postinfection during the period of observation. By six months postinfection nine females $(39 \cdot 1 \%)$ and two males $(8 \cdot 7 \%)$ were continuing to have active joint symptoms, with recurrent arthritis noted in four individuals. By 18 to 24 months postinfection, seven of 23 females $(30.4 \%)$ were continuing to experience recurrent episodes of either arthritis (four cases) or arthralgia (three cases), and two of 23 males $(8.7 \%)$ were also experiencing recurrent arthritis (one case) or arthralgias (one case).

\section{Discussion}

The present study documents the critical role played by rubella virus strain differences in determining the incidence, severity, and duration of rubellaassociated arthropathy. Infection with wild strains of rubella virus was associated with the development of acute polyarticular arthritis in $30.4 \%$ of mixed adult populations, with a significantly higher incidence of arthritis noted among females $(52 \cdot 2 \%)$ than among males $(8.7 \%)$. The high incidence of arthritis observed after wild rubella infection is consistent with early reports of rubella-associated arthritis in $20 \cdot 8,34 \cdot 7$, and $32 \cdot 0 \%$ of mixed adult populations during rubella epidemics occurring in $1918,{ }^{9} 1940,{ }^{10}$ and $1953^{11}$ respectively. Early reports ${ }^{11}{ }^{12}$ noted a female preponderance among symptomatic cases but did not specifically outline differences in the incidence of arthritis among males and females. It is unlikely that ascertainment bias alone can account for the higher incidence of more severe forms of joint symptoms, i.e., objective arthritis, in the wild rubella infection group than in the RA $27 / 3$ rubella vaccine group. All high school students and staff developing a rash during the epidemic period were evaluated and previous studies ${ }^{6}$ have failed to detect differences in the risk of arthritis among rubella vaccinees developing or not developing a rash during the postvaccine period. In addition, the younger age profile of the wild rubella group would, if anything, give a lower frequency of joint manifestations in view of the known association of rubella-associated arthritis with increasing age. ${ }^{13}$
Perhaps the most striking feature of the present study is the observation that a significant proportion of both vaccine and witd rubella infection groups developed prolonged or recurrent joint manifestations lasting over 18 months postinfection. Previous studies have placed particular emphasis on acute transient joint manifestations, ${ }^{1}{ }^{2}$ 9-12 $14-18$ whereas fewer studies have examined the duration of symptoms for prolonged periods postinfection. ${ }^{3-5} 19$ The present study documents continuing active joint manifestations of 18 months or longer duration in $4.5 \%$ of the vaccine study group and $30.4 \%$ of females and $8.7 \%$ of males in the wild rubella study group. In both vaccine and wild rubella infection groups continuing joint symptoms occurred far more frequently in individuals presenting initially with arthritis than in those presenting with arthralgias.

This work was supported by grants from the Medical Research Council of Canada, the British Columbia Health Care Research Foundation, and the Arthritis Society of Canada. We thank the student volunteers, Audrey Fell and Dr R Percival-Smith of the Student Health Service at the University of British Columbia for their assistance in the rubella vaccine study group; Joan Lansdell and Nancy MacInnis of the South Okanagan Health Unit, Penticton, British Columbia for their assistance in follow up of the wild rubella infection group; and Anne Sinclair for preparation of the manuscript.

\section{References}

1 Dudgeon J A, Marshall W C, Peckham C S. Rubella vaccine trials in adults and children. Am J Dis Child 1969; 118: 237-42.

2 Best J M, Banatvala J E, Bowen J M. New Japanese rubella vaccine: comparative trials. $\mathrm{Br}$ Med J 1974; iii: 221-4.

3 Ogra P L, Herd J K. Arthritis associated with induced rubella infection. J Immunol 1971; 107: 810-3.

4 Spruance S L, Metcalf R M, Smith C B, Griffiths M M, Ward $J$ R. Chronic arthropathy associated with rubella vaccination. Arthritis Rheum 1977; 20: 741-7.

5 Chantler J K, Ford D K, Tingle A J. Persistent rubella infection and rubella-associated arthritis. Lancet 1982; i: 1323-5.

6 Tingle A J, Yang T, Allen M, Kettyls G D, Larke B, Schulzer M. Prospective immunological assessment of arthritis induced by rubella vaccine. Infect Immun 1983; 40: 22-8.

7 Tingle A J, Kettyls G D M, Ford D K. Studies on vaccineinduced rubella arthritis: serologic findings before and after immunization. Arthritis Rheum 1979; 22: 400-1.

8 Parkman P D, Hopps H E, Meyer H M Jr. Rubella virus: isolation, characterization and laboratory diagnosis. Am J Dis Child 1969; 118: 68-77.

9 Geiger J C. Epidemic of German measles in a city adjacent to an army cantonment: JAMA 1918; 70: 1818-20.

10 Hope Simpson R E. Rubella and polyarthritis. Br Med J 1940; i: 830.

11 Louden I S L. Polyarthritis in rubella. Br Med J 1953; i: 1388.

12 Lewis G W. Polyarthritis in rubella. Br Med J 1953; ii: 149-50.

13 Weibel R E, Stokes J Jr, Buynak E B, Hilleman M R. Influence of age on clinical responses to HPV-77 duck rubella vaccine. JAMA 1972; 222: 805-7. 
14 Freestone D S, Prydie J, Hamilton Smith S G, Laurence G. Vaccination of adults with Wistar RA $27 / 3$ rubella vaccinc. $J$ Hyg (Camb) 1971; 69: 471-7.

15 Polk B F, Modlin J F, White J A, DeGirolami P C. A controlled comparison of joint reactions among women receiving one of two rubella vaccines. Am J Epidemiol 1982; 115: 19-25.

16 Gershon A A, Frey H M. Borkowsky W. Steinberg S. Live attenuated rubella virus vaccine: comparison of responses to HPV-77-DE5 and RA 27/3 strains. Am J Med Sci 1980; 279: 95-7.
17 Wcibel R E, Villarejos V M. Klein E B. Buynak E. B, McLean A. Hilleman M R. Clinical and laboratory studies of live attenuated RA 27/3 and HPV 77-DE rubella virus vaccines. Proc Soc Exp Biol Med 1980; 165: 44-9.

18 Fogel A. Moshkowitz A. Rannon L, Gerichter Ch B. Compara के tive trials of RA $27 / 3$ and Cendehill rubella vaccines in adult an adolescent females. Am J Epidemiol 1971; 93: 392-8.

19 Smith M F. Haycock G B. Grahame R. Rubella and juvenile chronic arthritis. Arch Dis Child 1981; 56: 310-1. 